\title{
Perovskite membranes by aqueous combustion synthesis: synthesis and properties
}

\author{
Alexander S. Mukasyan, Colleen Costello, Katherine P. Sherlock, \\ David Lafarga, Arvind Varma* \\ Department of Chemical Engineering, University of Notre Dame, Notre Dame, IN 46556 USA
}

\begin{abstract}
The objective of this work is to identify optimum synthesis, compacting and sintering conditions in order to achieve a pure phase fully densified $\mathrm{La}_{0.8} \mathrm{Sr}_{0.2} \mathrm{CrO}_{3}$ (LSC) perovskite membrane. The aqueous combustion synthesis of LSC powders was investigated over a wide range of synthesis conditions by using the metal nitrates (oxidizer)-glycine (fuel) system. The powders were pressed and sintered to create dense materials, which were characterized. It was shown that depending on fuel/oxidizer ratio, $\varphi$, the reaction can proceed in three different modes: Smoldering Combustion Synthesis (SCS), $\varphi<0.7$, with maximum temperature, $T_{\mathrm{m}}<600^{\circ} \mathrm{C}$; Volume Combustion Synthesis (VCS), $0.7<\varphi<1.2,1150^{\circ} \mathrm{C}<T_{\mathrm{m}}<1350^{\circ} \mathrm{C}$; Self-propagating High-temperature Synthesis (SHS), $1.2<\varphi<1.6$, $800^{\circ} \mathrm{C}<T_{\mathrm{m}}<1100^{\circ} \mathrm{C}$. In turn, the characteristics of synthesized powders depend on the combustion mode. The crystalline structure of as-synthesized powders becomes more defined as $\varphi$ increases (amorphous for SCS; crystalline for VCS and SHS). The specific surface area decreases slightly when mode changes from SCS $\left(\sim 25 \mathrm{~m}^{2} \mathrm{~g}^{-1}\right)$ to VCS $\left(\sim 20 \mathrm{~m}^{2} \mathrm{~g}^{-1}\right.$ ), however, it increases substantially under SHS conditions (up to $45 \mathrm{~m}^{2} \mathrm{~g}^{-1}$ ). It was also shown that calcination is beneficial only for SCS powders, while VCS and SHS powders may be sintered directly as synthesized, thus bypassing the time and energy consuming calcination step. The measured oxygen permeation values for the membranes are comparable with the best candidate materials reported in the literature. (C) 2001 Elsevier Science B.V. All rights reserved.
\end{abstract}

Keywords: Perovskite membranes; Combustion synthesis; Membrane microstructure; Sintering; Oxygen selective transport

\section{Introduction}

Perovskites are inorganic complex oxides with the empirical formula $\mathrm{ABO}_{3}$, where A-site cations are typically rare earth metals, while B-sites are occupied by transition metals with mixed valence

\footnotetext{
* Corresponding author. Tel.: + 1-219-6316491; fax: + 1219-6318366.

E-mail address: avarma@nd.edu (A. Varma).
}

states. Some perovskites exhibit high mixed electronic and oxygen ionic conductivities, and for this reason are being widely studied for applications in solid oxide fuel cells (SOFCs), oxygen sensors and pumps, batteries, and oxygen-permeable membranes [1,2].

Among these materials, Lanthanum chromite (LC) perovskite shows high electronic conductivity, and stability under both oxidizing and reducing conditions. However, its applications are 
limited by poor sinterability in air, which can be improved by use of dopants such as Strontium and Calcium [3], but their effective use requires relatively high concentrations and very high sintering temperatures.

In the present work, we focus on the Sr-doped lanthanum chromites (LSCs). These perovskites are prepared by a variety of wet-chemical methods, including hydrothermal sol-gel synthesis, coprecipitation, spray-pyrolysis, liquid and amorphous citrates, and freeze-drying [4]. However, it remains a challenge to synthesize such powders rapidly, with desired phase composition, high purity, high surface area and narrow particle size distribution. The combustion synthesis (CS) technique offers a potential solution to this problem.

In general, CS is an energy-efficient method for the production of advanced materials, including powders and net-shape articles [5,6]. Characterized by fast heating rates, high temperatures, and short reaction times, CS occurs typically by two modes. In the self-propagating high-temperature synthesis (SHS) mode, powder reactants are heated locally and the reaction follows a wave-like propagation through the medium, while in volume combustion synthesis (VCS), reactants are heated uniformly and reaction occurs simultaneously throughout the mixture.

A modification of the CS method is aqueous combustion synthesis, which uses precursor aqueous solutions containing nitrates of the desired metals and a fuel, such as glycine, hydrazine, or urea. This process has been used to synthesize a variety (more than 100) of fine particle complex oxides, such as chromites, ferrites and zirconia [7-9]. Powders prepared by aqueous CS generally have high surface areas, as well as pure phase and chemical compositions. Chick et al. [10] have reported the only work available in the literature on the aqueous CS of LSC powders. They investigated a relatively narrow range of reaction mixture compositions (corresponding to the VCS mode), and did not report data on sinterability and other properties of materials.

In this paper, we investigate the aqueous $\mathrm{CS}$ of $\mathrm{La}_{0.8} \mathrm{Sr}_{0.2} \mathrm{CrO}_{3}$ powders over a wide range of synthesis conditions. The resulting powders are char- acterized for phase composition, microstructure and surface area. The powders are pressed and sintered to create dense materials, which are also characterized. The objective of this work is to identify optimum synthesis, compacting and sintering conditions in order to achieve a pure phase fully densified membrane.

\section{Experimental}

\subsection{Aqueous combustion synthesis of lanthanum strontium chromite powders}

Aqueous $\mathrm{CS}$ of $\mathrm{La}_{0.8} \mathrm{Sr}_{0.2} \mathrm{CrO}_{3}$ perovskite was conducted by using the metal nitrates-glycine system. In this case, the overall combustion reaction can be represented as follows:

$$
\begin{aligned}
& 0.8 \mathrm{La}\left(\mathrm{NO}_{3}\right)_{3} \cdot 6 \mathrm{H}_{2} \mathrm{O}_{(\mathrm{c})}+0.2 \mathrm{Sr}\left(\mathrm{NO}_{3}\right)_{2(\mathrm{c})} \\
& +\mathrm{Cr}\left(\mathrm{NO}_{3}\right)_{3} \cdot 9 \mathrm{H}_{2} \mathrm{O}_{(\mathrm{c})}+n \mathrm{H}_{2} \mathrm{~N}\left(\mathrm{CH}_{2}\right) \mathrm{CO}_{2} \mathrm{H}_{(\mathrm{c})} \\
& +(2.25 n-7.2) \mathrm{O}_{2(\mathrm{~g})} \Rightarrow \mathrm{La}_{0.8} \mathrm{Sr}_{0.2} \mathrm{CrO}_{3(\mathrm{c})} \\
& +\left[2 n \mathrm{CO}_{2}+(13.8+2.5 n) \cdot \mathrm{H}_{2} \mathrm{O}\right. \\
& \left.+(n / 2+2.9) \mathrm{N}_{2}\right]_{(\mathrm{g})} \uparrow .
\end{aligned}
$$

Some characteristics of the chemical reagents (Aldrich) are given in Table 1. The ratio between nitrates (oxidizers) was maintained constant corresponding to the desired phase composition, while ratio between glycine (fuel) and oxidizer (metal nitrates), $\varphi$, was changed. Note that the stoichiometric ratio $(\varphi=1)$ corresponds to the situation where $\mathrm{La}_{0.8} \mathrm{Sr}_{0.2} \mathrm{CrO}_{3}$ composition can be formed directly from the reaction between fuel and oxidizer, with no additional oxygen required $(n=$ 3.2).

The fuel and oxidizers were mixed in distilled water, thoroughly stirred to reach complete dissolution of all solid reagents, and placed on a hot

Table 1

Some characteristics of used powders

\begin{tabular}{lll}
\hline Powder & Purity $(\%)$ & Melting point $\left({ }^{\circ} \mathrm{C}\right)$ \\
\hline $\mathrm{H}_{2} \mathrm{~N}\left(\mathrm{CH}_{2}\right) \mathrm{CO}_{2} \mathrm{H}$ & 98 & $240-245$ \\
$\mathrm{La}\left(\mathrm{NO}_{3}\right)_{3} \cdot 6 \mathrm{H}_{2} \mathrm{O}$ & 99.9 & 40 \\
$\mathrm{Cr}\left(\mathrm{NO}_{3}\right)_{3} \cdot 9 \mathrm{H}_{2} \mathrm{O}$ & 99 & 60 \\
$\mathrm{Sr}\left(\mathrm{NO}_{3}\right)_{2}$ & 99 & 570 \\
\hline
\end{tabular}


plate (Cole-Parmer) to initiate the reaction. A two-wave length pyrometer (Ircon MR-OR1099C) and thermal video system (TVS-2000MkII, Cincinnati Electronic Corp.) were used to record the process temperature-time history. As temperature reached $100^{\circ} \mathrm{C}$, water started to boil and evaporate from the solution, which increased solution viscosity substantially, culminating in rapid reaction. Depending on the value of $\varphi$, synthesis of perovskite powder occurred in three different regimes (see Section 3.1 for details).

The as-synthesized powders were generally heat-treated (calcined) in air atmosphere. Specifically, powders were mounted in a hollow boron nitride cylinder, and calcined at $850^{\circ} \mathrm{C}$ for $12 \mathrm{~h}$. There are two main reasons for this procedure. The first is to remove residual water and other easily volatile components, while the second is to improve crystalline structure of the powders. The latter is especially important in the case of powders produced from initial mixtures with $\varphi<0.7$, which have amorphous structure immediately following CS. However, it appears that calcination also influences the microstructure of the powders (see Section 3.2).

\subsection{Perovskite membrane preparation}

Following calcination, the powders were pressed in stainless steel cylindrical dies with diameters 13 and $30 \mathrm{~mm}$, to produce green disks with thickness 1-2 $\mathrm{mm}$. Using automatic hydraulic press (Carver, Inc., 'Auto' series), the powder was subjected to uniaxial pressure in the range 2000-25 $000 \mathrm{lbs}$, for a period $30-60 \mathrm{~s}$. The obtained disks had initial densities in the range $20-60 \%$ of theoretical value.

To achieve higher final density, the green samples were sintered in air atmosphere. For this, the disks were mounted on a boron nitride platform and heat treated for $10 \mathrm{~h}$ at temperature $1600^{\circ} \mathrm{C}$, using a high-temperature split-tube furnace (Thermcraft).

\subsection{Materials characterization}

Several techniques were used for comprehensive analysis and characterization of the synthesized powders and materials. Phase composition analysis was conducted using a Rigaku X-Ray Diffractometer (XRD). To investigate the product microstructure, a scanning electron microscope (SEM, JEOL) was utilized, primarily in the Second Electron Images (SEI) mode. Finally, the BET surface area of powders was measured by using the nitrogen adsorption/desorption method (Autosorb-1, Quantachrome).

A gas-tight electrochemical cell was used to measure the oxygen permeability in steady-state conditions. Details about the setup are given elsewhere [11]. The device allows achieving reduced oxygen environments in the cell, using flowing air as the surrounding reference atmosphere. The sintered membrane was polished to the appropriate thickness $(\sim 1.3 \mathrm{~mm})$, and its sides were covered with Pyrex glass to prevent oxygen from entering. Under steady state conditions, the amount of oxygen entering the cell (by permeating through the membrane) equals that pumped out. In this case, oxygen flow through the membrane can be determined as follows:

$j \mathrm{O}_{2}=\frac{I}{4 F S}$,

where $j \mathrm{O}_{2}$ is oxygen flux $\left(\mathrm{mol} \mathrm{cm}{ }^{-2} \mathrm{~s}^{-1}\right), I$ the pumping current (A), $S$ the effective cross-sectional area of membrane $\left(\mathrm{cm}^{2}\right)$ and $F$ the Faraday's constant.

\section{Results}

\subsection{Combustion synthesis}

The plot of maximum reaction temperature as a function of fuel/oxidizer ratio, $\varphi$, as well as the characteristic combustion regimes is shown in Fig. 1. As noted above, depending on $\varphi$, the reaction can proceed in three different modes:

1. Smoldering Combustion Synthesis (SCS), $\varphi<$ 0.7 , with maximum temperature, $T_{\mathrm{m}}<600^{\circ} \mathrm{C}$;

2. Volume Combustion Synthesis (VCS), $0.7<$ $\varphi<1.2,1150^{\circ} \mathrm{C}<T_{\mathrm{m}}<1350^{\circ} \mathrm{C}$;

3. Self-propagating High-temperature Synthesis (SHS), $1.2<\varphi<1.6,800^{\circ} \mathrm{C}<T_{\mathrm{m}}<1100^{\circ} \mathrm{C}$. 


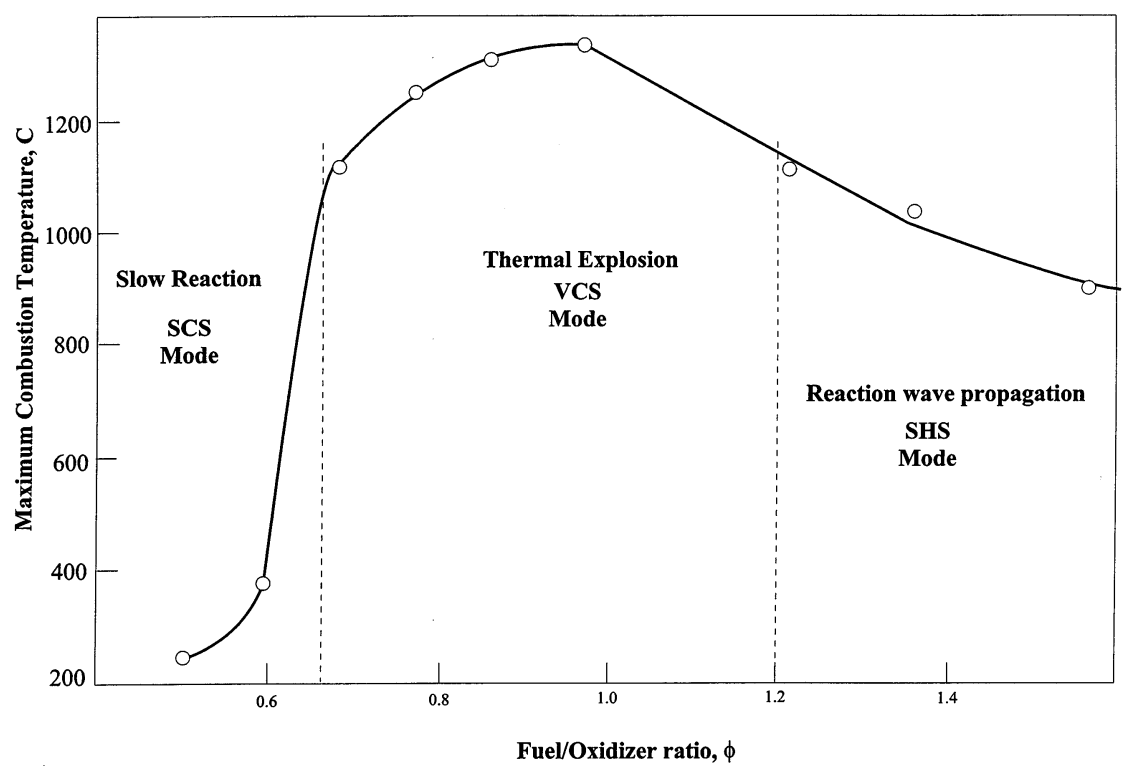

Fig. 1. Maximum combustion temperature achieved for different combustion modes as a function of the fuel/oxidizer ratio.

The SCS mode is characterized by relatively slow, essentially flameless reaction, with formation of an amorphous ash as solid product. Extremely fast (explosion-type) reaction characterized the VCS mode. In this case, the reaction occurs essentially simultaneously in the solution volume. Finally, the characteristic feature of the SHS mode is that reaction initiates locally and propagates as a combustion wave in a selfsustained manner through the reaction volume.

\subsection{Characterization of as-synthesized powders}

It appears that different powders synthesized in the SCS mode are amorphous; no peaks can be identified on the XRD patterns (Fig. 2a). However, the VCS and SHS powders have identical well-defined crystalline structures (Fig. 2b). A search-match database analysis confirmed that these powders have phase composition of $\mathrm{La}_{0.8} \mathrm{Sr}_{0.2} \mathrm{CrO}_{3}$ perovskite.

The characteristic microstructure of SCS powder is presented in Fig. 3a. It may be seen that agglomerates involved thin $(100 \mathrm{~nm})$ flakes with smooth surface, perforated by many large pores. Fig. 3b shows typical morphology of VCS pow- ders. It is interesting that despite different synthesis conditions, this microstructure is similar to the previous one. On the other hand, the SHS powder has somewhat different morphology (see Fig. 3c). In this case, the surface pores decrease substantially and conglomerates are not thin flakes but waffles, which have complex high surface area network structure. The data for specific surface area of different powders are presented in Table 2 . It can be seen that SHS powder has larger specific surface as compared to the SCS and VCS products.

\subsection{Characterization of calcined powders}

The mass of SCS powder decreased after calcination, up to $20 \%$, while mass loss of VCS and SHS powders was not more than $1 \%$. The X-ray diffraction analysis shows that upon calcination, the amorphous as-synthesized SCS powders became well crystalline with phase composition similar to those for VCS and SHS powders. The latter remained essentially unchanged in phase composition during calcination. However, the peaks of all calcined powders exhibited a reduction in broadness as compared to the corresponding as-synthesized patterns. 
It is remarkable that microstructures of all powders changed dramatically with calcination (compare Fig. $3 \mathrm{a}-\mathrm{c}$ and $\mathrm{d}-\mathrm{f}$ ). It can be seen that the calcined powders do not exhibit flake or waffle type microstructure and are extremely uniform with well defined morphology of each particle. Also, the characteristic size of particles increased after calcination. This leads to large decreases in specific surface area of powders as shown in Table 2. Note that the powder synthesized in SHS mode is the most homogeneous and with the highest surface area among all calcined samples.

\subsection{Compacting and sintering}

To produce fully dense membrane by sintering, it is favorable to have high initial density of green disks. The latter can be achieved by increasing applied load during pressing. However, above a certain threshold load, disks could not maintain integrity and would fracture or cleave. For example, for the $13 \mathrm{~mm}$ diameter press-die, samples compacted from as-synthesized SCS powders were observed to have threshold load $\sim 20000 \mathrm{lb}$, while for uncalcined VCS and SHS powders it was only $12000 \mathrm{lb}$. Disks pressed from calcined
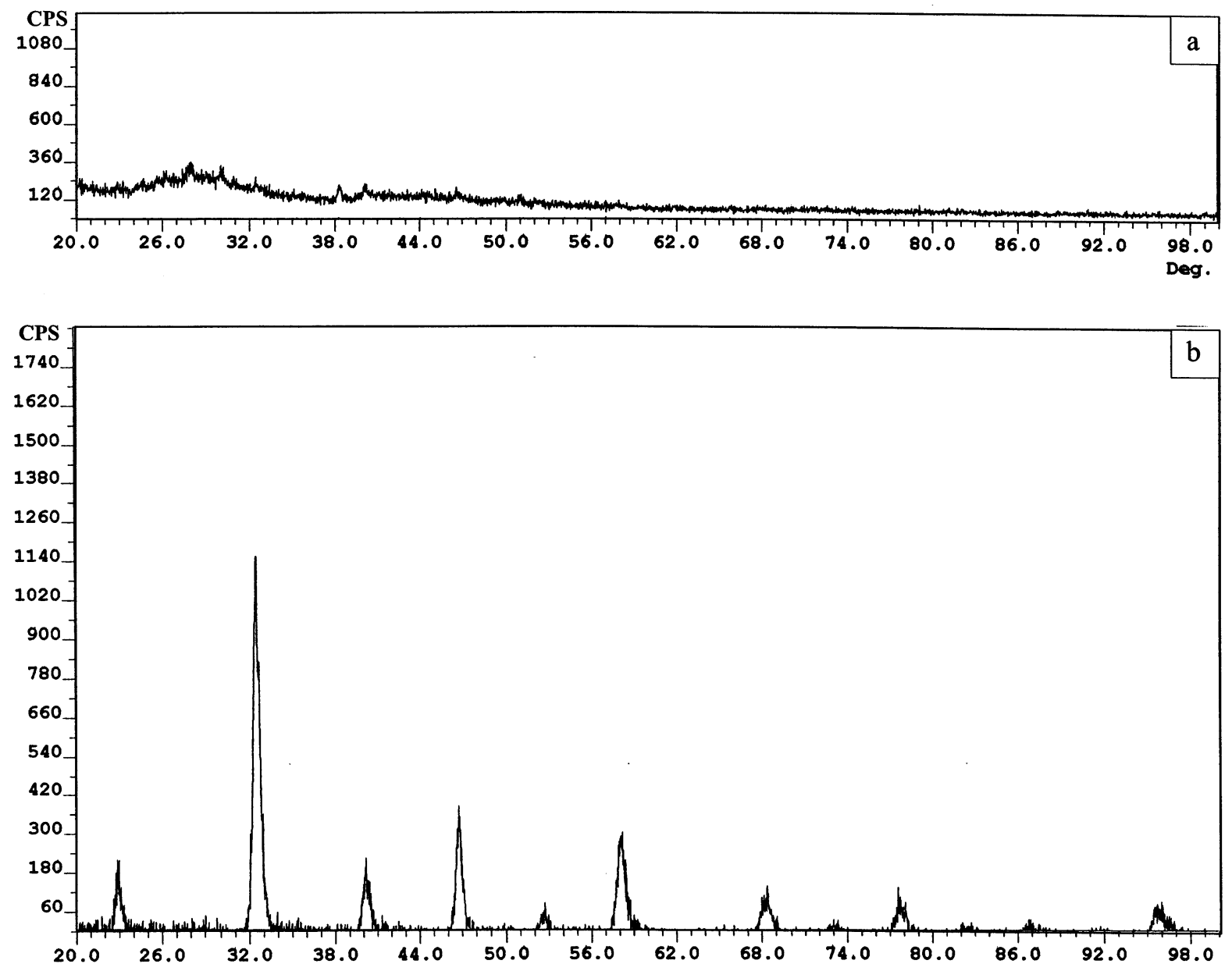

Fig. 2. XRD patterns for as-synthesized powders by (a) SCS, and (b) VCS/SHS modes. 

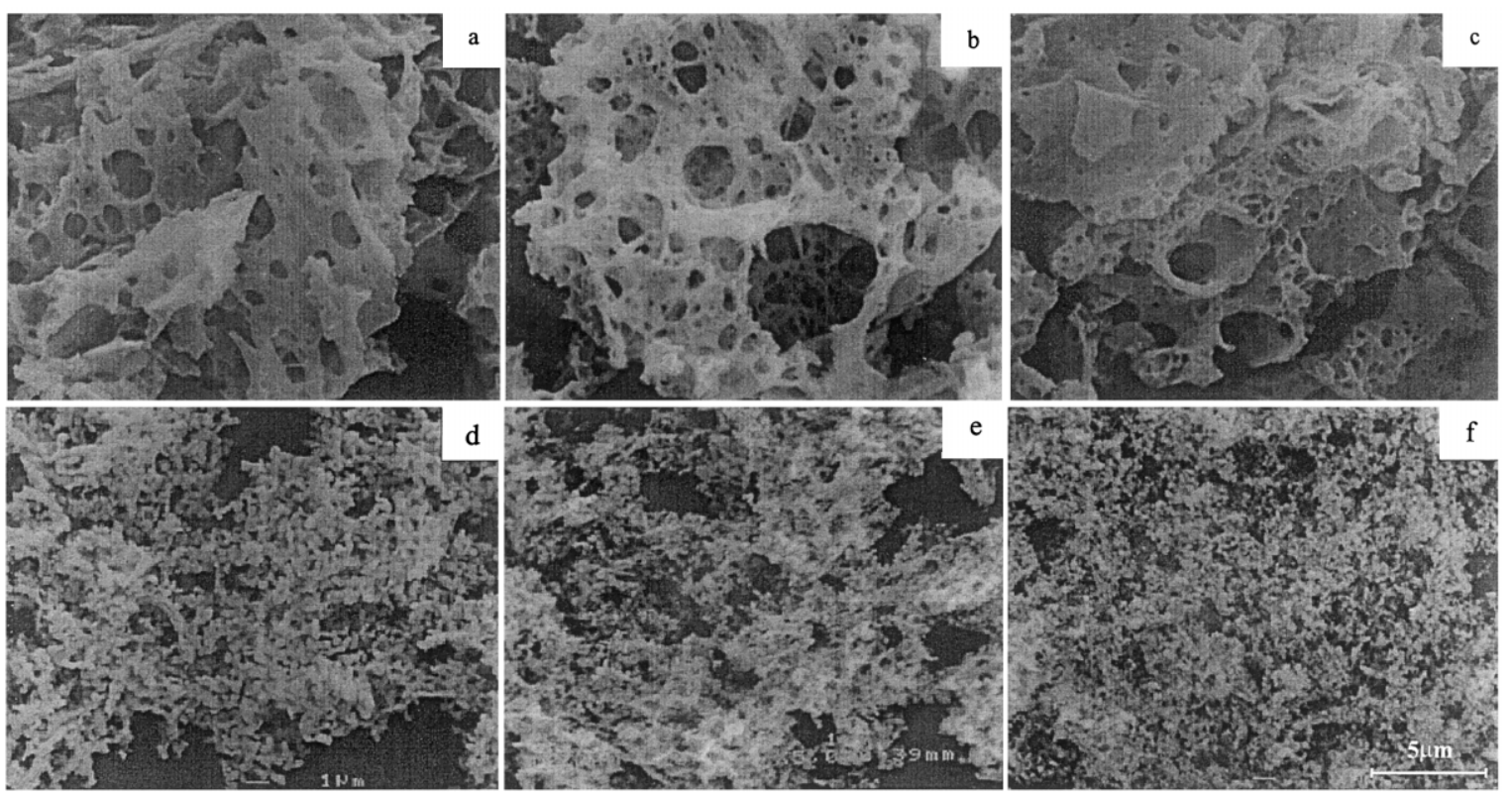

Fig. 3. Characteristic microstructures of $(\mathrm{a}-\mathrm{c})$ as-synthesized and $(\mathrm{d}-\mathrm{f})$ calcined LSC powders produced by (a, d) SCS, (b, e) VCS, and (c, f) SHS modes. Magnification: $5000 \times$.

powders had much lower threshold ( 2400 lb). Note that for maintaining final material purity, no binder was used. In Table 3, relative densities of green disks at the threshold load are presented. It can be seen that different as-synthesized powders can be compacted to essentially the same initial density. Also, calcination in general leads to increasing initial sample density, which is related to the microstructural transformations occurring during calcination.

The pressed disks were sintered following the procedure described in Section 2.2. A shrinkage in height and diameter was observed in all sintered disks. The data for final sample densities reached after sintering are presented in Table 3.

\subsection{Microstructure of perovskite membranes}

Cross sections of sintered membranes were prepared and examined in the SEI mode. The characteristic microstructure of membrane sintered from uncalcined SCS powder is shown in Fig. 4a. This membrane has a final relative density of $69 \%$, and average grain size $2 \mu \mathrm{m}$. It may be seen that a number of relatively large pores $(\sim 10 \mu \mathrm{m})$ char- acterize the structure. Essentially no large pores are observed when disk of the SCS calcined powder was sintered (Fig. 4d) which yields higher final density (77\%); however, the grain size is larger (4 $\mu \mathrm{m})$. Although the microstructure is uniform, there are noticeable gaps between particles and overall particle boundaries are distinct. A higher magnification of this sample is also shown in Fig. $4 \mathrm{~d}$, and reveals only initial stages of neck formation between the grains.

Fig. $4 \mathrm{~b}$ represents the typical cross-section of a membrane (relative density $72 \%$ ) produced from uncalcined VCS powder. This uniform microstructure is characterized by grains of $1.5 \mu \mathrm{m}$ diameter, narrow particle size distribution and

\section{Table 2}

Characteristic surface areas of powders synthesized in different combustion modes

\begin{tabular}{lll}
\hline Powder type & $\begin{array}{l}\text { Specific surface area } \\
\text { of as-synthesized } \\
\text { powder }\left(\mathrm{m}^{2} \mathrm{~g}^{-1}\right)\end{array}$ & $\begin{array}{l}\text { Specific surface area } \\
\text { of calcined powder } \\
\left(\mathrm{m}^{2} \mathrm{~g}^{-1}\right)\end{array}$ \\
\hline SCS & 27 & 2 \\
VCS & 20 & 6 \\
SHS & 41 & 24 \\
\hline
\end{tabular}


Table 3

Relative initial and final density of perovskite membranes

\begin{tabular}{llllll}
\hline Powder type & Calcination & Load (lbs) & $\begin{array}{l}\text { Initial relative } \\
\text { density }(\%)\end{array}$ & $\begin{array}{l}\text { Final relative } \\
\text { density }(\%)\end{array}$ & $\begin{array}{l}\text { Increase of density after sintering } \\
(\%)\end{array}$ \\
\hline SCS & No & 20000 & 43 & 59 & 16 \\
VCS & No & 12000 & 46 & 72 & 26 \\
SHS & No & 12000 & 44 & 77 & 33 \\
SCS & Yes & 2400 & 52 & 77 & 38 \\
VCS & Yes & 2400 & 52 & 80 & 38 \\
SHS & Yes & 2400 & 47 & 85 & \\
\hline
\end{tabular}
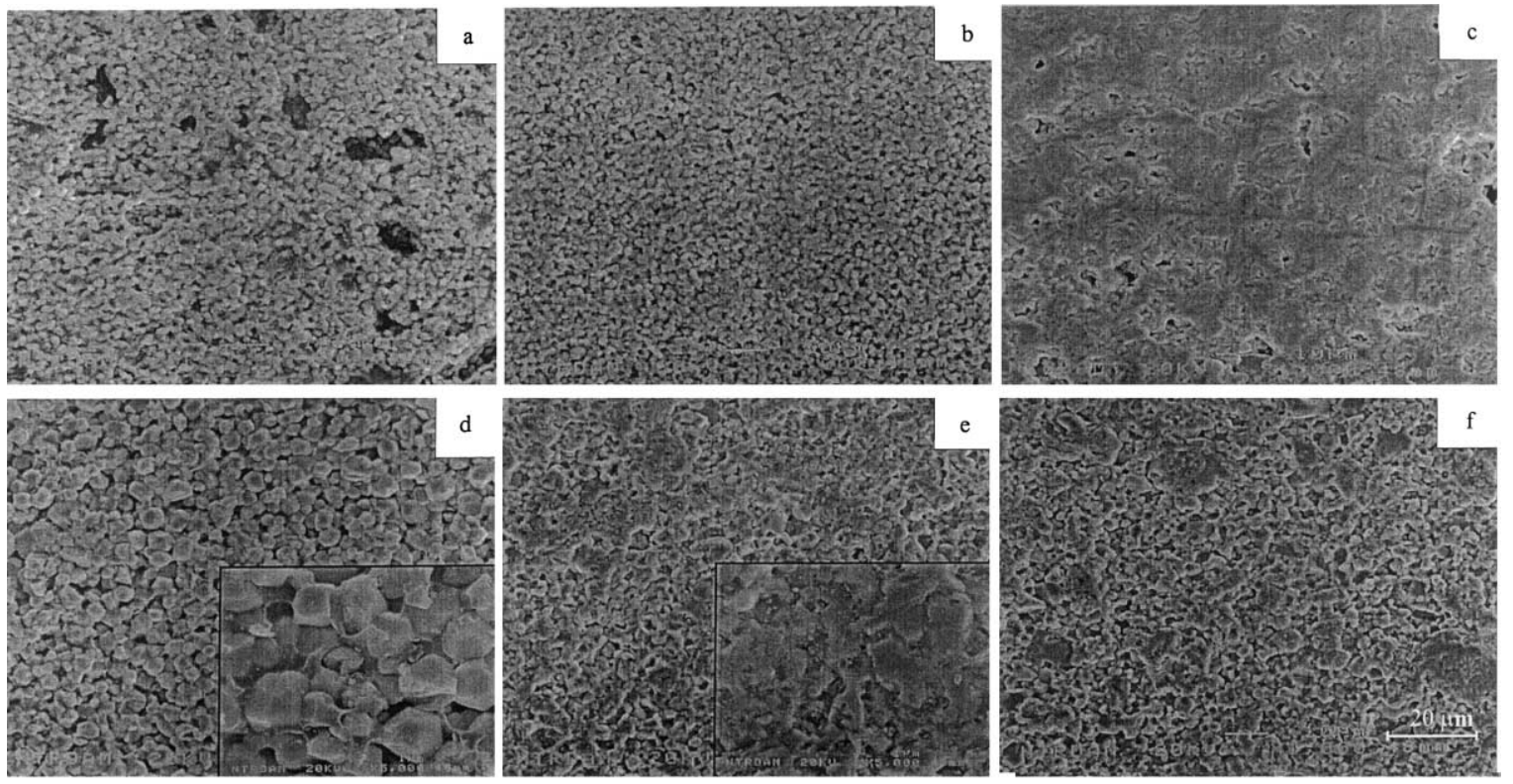

Fig. 4. Characteristic microstructures of (a, c, e) uncalcined and (b, d, f) calcined sintered LSC powders produced by (a, b) SCS, (c, d) VCS, and (e, f) SHS modes. Magnification: $\times 1000$.

absence of large pores. Fig. 4e shows the microstructure of membrane sintered from calcined VCS powder, which reached relative density of $90 \%$. A higher magnification of this sample shows that in this case formation of necks leads to loss of particle distinction.

Fig. 4c shows the sintered cross-section of a membrane produced from SHS powders that were not previously subjected to calcination. This membrane reached a sintered relative density of $77 \%$. There are virtually no distinct particles visible in this sample, however several relatively large $(2-5 \mu \mathrm{m})$ irregular-shaped pores can be observed.
The sample (relative density $85 \%$ ) sintered form SHS calcined powders is shown in Fig. 4f, which exhibits similar characteristics as membrane from the calcined VCS powder (Fig. 4e).

\subsection{Oxygen permeability of perouskite membranes}

The oxygen transport rate through the perovskite membranes was measured in the range $650-850^{\circ} \mathrm{C}$ using the approach discussed in Section 2.3. The oxygen flux through the sample (1.3 $\mathrm{mm}$-thick disk; SCS-calcined) as a function of 
oxygen pressure inside the cell at five different temperatures is shown in Fig. 5. It may be seen that oxygen permeability increases with both increasing temperature and oxygen partial pressure gradient. For example, at $850^{\circ} \mathrm{C}$, the oxygen permeability is $\sim 2 \times 10^{-7} \mathrm{~mol} \mathrm{~cm} \mathrm{~cm}^{-2}$ at $\Delta \log \left(\mathrm{pO}_{2}\right)=1.5$.

\section{Discussion}

\subsection{Combustion synthesis of powders}

In Fig. 6, it is seen how characteristics of synthesized powders depend on the combustion mode (or $\varphi$ ). Progressive increase of fuel amount

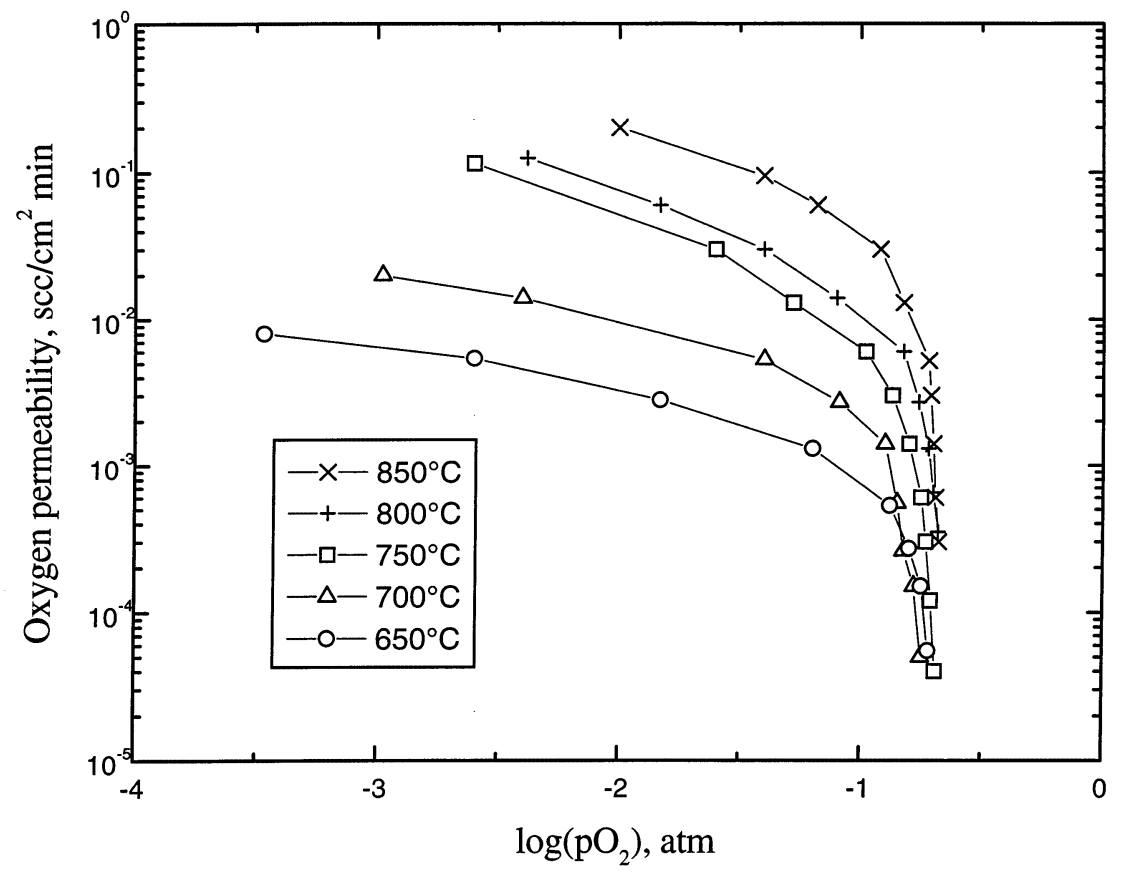

Fig. 5. Oxygen permeability of sintered LSC disk $(\phi=0.5)$ as a function of oxygen partial pressure inside the cell and different temperatures.

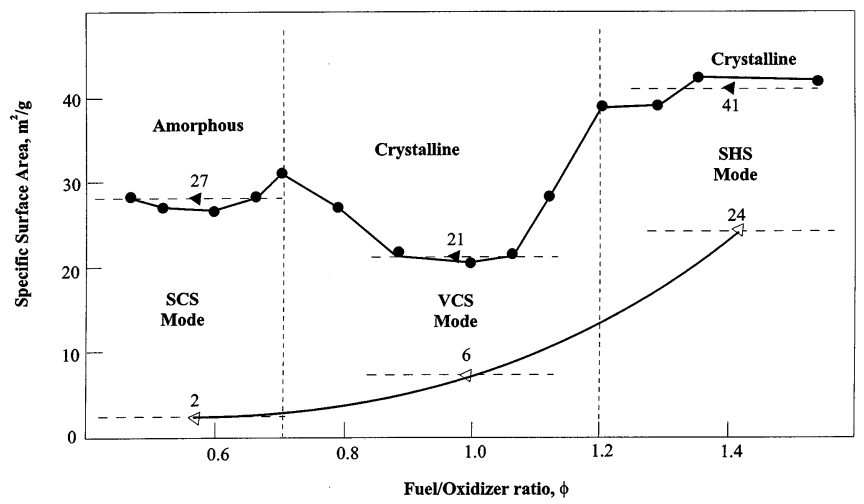

Fig. 6. Characteristics of synthesized powders, combustion modes and BET surface areas as functions of the fuel/oxidizer ratio; open symbols — as-synthesized, filled symbols — calcined. 
$(\varphi)$ leads to the following sequence of reaction modes: SCS $\rightarrow$ VCS $\rightarrow$ SHS. Simultaneously, the crystalline structure of as-synthesized powders becomes more defined (amorphous for SCS $\rightarrow$ crystalline for VCS and SHS). The specific surface area decreases slightly, when mode changes from SCS to VCS, however under SHS conditions it increases substantially. All these changes can be explained based on the temperature-time characteristics of the reaction modes. Thus, relatively low temperature $\left(600^{\circ} \mathrm{C}\right)$ during SCS does not allow for crystalline structure to form. However, long time of reaction (minutes) leads to the relatively low $\left(\sim 25 \mathrm{~m}^{2} \mathrm{~g}^{-1}\right)$ specific surface area. At high temperatures $\left(>1300^{\circ} \mathrm{C}\right)$ of VCS mode, the crystalline structure of formed perovskite is well defined, which occurs even during very short $(\sim$ $1-5$ s) reaction time. On the other hand, these high temperatures lead to some decrease of powder specific surface area (up to $20 \mathrm{~m}^{2} \mathrm{~g}^{-1}$ ). Decrease of reaction temperature as well as short reaction time $(\sim 5 \mathrm{~s})$, which characterizes the SHS mode, results in large increase of powder surface area (up to $45 \mathrm{~m}^{2} \mathrm{~g}^{-1}$ ). It is interesting that in this case the temperature is still high enough to produce desired crystalline structure. Thus powders with both fine microstructure ( $100 \mathrm{~nm} ; 45 \mathrm{~m}^{2} \mathrm{~g}^{-1}$ ) and developed crystallinity can be directly formed only during reaction in the SHS mode. It is remarkable that SHS powders produced at higher temperatures have much higher specific surface area as compared to SCS powders synthesized at much lower temperatures.

\subsection{Calcination}

The first effect of calcination process is in general favorable, predictable and related to the improvement of crystalline structure of as-synthesized powders. In fact, XRD analysis revealed that this additional heat treatment transformed the SCS powder from amorphous to crystalline form. This process also removed residual carbon and other impurities. For VCS and SHS powders, it was shown that after calcination all characteristic peaks became more intense and narrower. The second effect is not obvious and is related to the substantial changes in all powder microstructures. On one hand, calcined powders have more uniform morphologies (see Fig. 3), which is a positive effect. On the other hand, specific surface areas of powders decrease (see Table 2), which is negative because it diminishes sinterability. All these observations lead to the conclusion that calcination may be beneficial only for SCS powders, while VCS and SHS powders may be sintered directly as synthesized, thus bypassing the time and energy consuming calcination step.

\subsection{Membrane preparation}

It was observed that calcined powders, as compared to as-synthesized ones, have much lower threshold loads above which defects formed during compacting. This is related to changes of morphology and specific surface area of powders that occur during calcination. However, even under these lower loads, higher initial densities were obtained for calcined powders (see Table 3). Note that this effect is more pronounced for powders synthesized from solutions with lower $\varphi$ compositions. For example, the differences in initial sample densities, between calcined and as-synthesized powders, are 9, 6 and 3\% for SCS, VCS and SHS modes, respectively. Thus, compactability of SHS powders is not much enhanced by the calcination procedure, again suggesting that this step may be omitted.

It is apparent that two main factors influence the final membrane density reached after sintering at high temperature $\left(1600^{\circ} \mathrm{C}\right)$ : initial sample density and powder sinterabilty. The former is higher for powders with lower surface area, while the latter is favored for those with higher surface area (Tables 2 and 3). Because these two factors have opposite dependence on surface area, some optimization is required to reach the highest density of sintered membrane. From Table 3, it appears that the calcined VCS powder leads to the highest theoretical density (90\%). However, microstructure of sintered uncalcined SHS powder is in general more dense than all others (see Fig. 4), except for isolated regions containing large pores. The reason for these pores may be small amount of low volatile impurities that remain in as-syn- 
Table 4

Permeation data of representative oxygen conductors

\begin{tabular}{|c|c|c|c|c|c|}
\hline Materials & Flux $\left(\mathrm{mol} \mathrm{cm} \mathrm{cm}^{-2} \mathrm{~s}\right)$ & Temperature $\left({ }^{\circ} \mathrm{C}\right)$ & Thickness (mm) & $\Delta \mathrm{PO}_{2}(\mathrm{~atm})$ & Reference \\
\hline $\mathrm{La}_{0.8} \mathrm{Sr}_{0.2} \mathrm{CrO}_{3}$ & $2 \times 10^{-7}$ & 850 & 1.3 & 0.20 & This work \\
\hline $\mathrm{SrFeCo}_{0.5} \mathrm{O}_{x}$ & $10^{-7}$ & 850 & 2.9 & 0.20 & {$[12]$} \\
\hline $\mathrm{La}_{0.3} \mathrm{Sr}_{0.7} \mathrm{CoO}_{3-\delta}$ & $1.6 \times 10^{-6}$ & 1100 & 0.6 & 0.21 & [13] \\
\hline $\mathrm{La}_{0.4} \mathrm{Sr}_{0.6} \mathrm{CoO}_{3-\delta}$ & $4 \times 10^{-7}$ & 1150 & 1 & 0.21 & [14] \\
\hline $\mathrm{Y}_{0.05} \mathrm{Ba}_{0.95} \mathrm{CoO}_{x}$ & $5 \times 10^{-8}$ & 900 & 2 & 0.21 & [15] \\
\hline
\end{tabular}

thesized SHS powders. It is expected that these impurities can be removed by low temperature heat treatment $\left(\sim 400^{\circ} \mathrm{C}\right)$, which simultaneously should not significantly decrease powder surface area. The optimization of conditions for synthesis of fully dense perovskite membranes prepared from SHS powders is currently in progress.

\subsection{Membrane oxygen permeability}

As observed in Fig. 5, oxygen permeability increased with increasing temperature and oxygen partial pressure gradient. The increase is sharp at low gradients and asymptotic when oxygen pressure inside the cell approaches zero. The temperature dependence and magnitude of oxygen flux indicate that the membrane is fully dense for permeation, suggesting that remaining porosity is closed.

Table 4 shows different oxygen permeation values from the literature for other representative candidate materials and LSC synthesized in this work. Taking into account the different conditions (thickness and temperature), LSC exhibits permeation performance comparable with the best.

\section{Acknowledgements}

We gratefully acknowledge financial support from the National Science Foundation (grants
CTS-9900357 and CTS-9907321). We also thank Drs U. Balachandran and B. Ma from Argonne National Laboratory for conducting the oxygen permeation measurements.

\section{References}

[1] B.C.H. Steele, Mater. Sci. Eng. B13 (1992) 79.

[2] N.Q. Minh, J. Am. Ceram. Soc. 76 (1993) 563.

[3] M. Mori, Y. Hiei, N.M. Sammes, Solid State Ionics 103 (1999) 123.

[4] P. Cousin, R.A. Ross, Mater. Sci. Eng. A130 (1990) 119.

[5] J.J. Moore, H.J. Feng, Prog. Mater. Sci. 39 (1995) 243.

[6] A. Varma, A.S. Rogachev, A.S. Mukasyan, S. Hwang, Adv. Chem. Eng. 24 (1998) 79.

[7] K.C. Patil, S.T. Aruna, S. Ekambaram, Curr. Opin. Solid State \& Mat. Sci. 2 (1997) 158.

[8] M.M.A. Sekar, A. Halliyal, J. Am. Ceram. Soc. 81 (1998) 380 .

[9] S. Bhaduri, S.B. Bhaduri, E. Zhou, J. Mater. Res. 13 (1998) 156.

[10] L.A. Chick, L.R. Pederson, G.D. Maupin, J.L. Bates, L.E. Thomas, G.J. Exarhos, Mat. Lett. 10 (1990) 6.

[11] B. Ma, U. Balachandran, J.H. Park, C.U. Segre, J. Electrochem. Soc. 143 (1996) 1724.

[12] B. Ma, U. Balachandran, C.-C. Chao, J.H. Park, C.U. Segre, Ceram. Trans. 73 (1997) 169.

[13] C.H. Chen, H.J.M. Bouwmeester, R.H.E. van Doorn, H. Kruidhof, A.J. Burggraaf, Solid State Ionics 98 (1997) 7.

[14] N. Itoh, T. Kato, K. Uchida, K. Haraya, J. Memb. Sci. 92 (1994) 239.

[15] H.W. Brinkman, H. Kruidhof, A.J. Burggraaf, Solid State Ionics 68 (1994) 173.

[16] J. Han, Y. Zeng, G. Xomeritakis, Y.S. Lin, Solid State Ionics 98 (1997) 63. 